\title{
DENTAL HEALTH ATTITUDES OF OLDER ADULTS LIVING IN URBAN AREAS IN WEST POMERANIA, NW POLAND VS. THEIR DENTITION STATUS EXPRESSED IN DMFT
}

\author{
Elżbieta Dembowska, Łukasz Wilczyński \\ Department of Periodontology, Pomeranian Medical University, Szczecin, Poland
}

\begin{abstract}
INTRODUCTION: Assessment of dental health attitudes among older people in the region of West Pomerania, Poland, and a comparison with their dental status shown by the decayed, missing, and filled teeth (DMFT) index. MATERIAL AND METHODS: The study involved 294 people aged 65-74 years living in West Pomerania, NW Poland. The study was conducted in the city of Szczecin and the towns of Łobez and Police in 2014-2015. Interviews with the participants provided information on their health attitudes. Clinical examinations evaluated their dentition to produce a DMFT index.

RESULTS: The largest group of respondents (106 people, 36\%) visited the dentist once a year. Only 50.3\% ( $n=148$ ) visited the dentist because of a follow-up. As many as 3.7\% of patients used a toothbrush less than once a day or not at all, while $6.8 \%$ replaced their toothbrush less than once a year or not at all. Only $20.4 \%$ of the respondents cleaned their interdental spaces. The mean number of missing teeth, and the DMFT index were higher among older adults with the lowest level of health attitudes.

Conclusions: The examined older adults in West Pomerania showed inadequate dental health attitudes. Only a fraction reported a habit of cleaning interdental spaces. In general, health attitudes had a significant impact on the dental health of the examined older adults. This paper shows the need for systematic, standardised, and reproducible epidemiological studies in older adults.
\end{abstract}

KeY wORDs: Poland, oral health, oral hygiene, older adults.

J Stoma 2019; 72, 2: 83-89

DOI: https://

\section{INTRODUCTION}

In recent decades, the global proportion of older adults in the population has seen an unprecedented increase. In 2010 an estimated 8\% (524 million) of the world population were aged 65 years or older; by 2050 the number is predicted to reach $16 \%$ ( 1.5 billion). In less developed countries this will mean a $250 \%$ increase, and $71 \%$ in developed countries [29], which shows that proper care for older adults, including the field of dental prevention, is going to become a serious challenge. We must therefore strive to understand the dental problems of older patients and how they can be solved [25].

Changes in the oral cavity of elderly patients are a consequence of age, damage, and tissue wear, as well as certain age-related diseases $[1,28]$. The risk of developing at least one chronic disease is age-related; this also includes the oral cavity, with concurrent important risk factors such as inadequate diet, smoking, alcohol abuse, and stress [20]. Oral condition in older people

\section{JOURNAL OF} STOMATOLOGY CZASOPISMO STOMATOLOGICZNE

AdDress for CORRESPondence: Dr. Łukasz Wilczyński, Department of Periodontology, Pomeranian Medical University, 72 Powstańców Wielkopolskich St., 70-111 Szczecin, Poland, e-mail: 7wilczynski@gmail.com 
is noted primarily for dental deficiencies, tooth decay, periodontitis, dry mouth, precancerous lesions, and neoplastic diseases $[19,21]$. Poor oral health adversely affects the daily life of people, including mastication, food choice, weight, interpersonal relations, self-esteem, and quality of life $[5,8,10,15,16]$. Caries is the primary cause of loss of teeth in elderly patients, and tooth loss is the most significant negative factor of quality of life. Studies have shown wide capabilities of risk indicators and risk factors connected with caries in the elderly, for both medical and local conditions [22]. Medical conditions like Sjögren's syndrome or xerostomia caused by pharmacological agents, chemotherapy, or therapeutic radiation, or many others diseases are associated with caries $[14,17]$. Gingival recessions and the inability to maintain unobjectionable oral hygiene increase the risk of root caries in the elderly $[2,23]$. Reduced access to dental care caused by socioeconomic factors, disability, reduced oral health aspirations, or low self-efficacy may predispose older adults to caries. Individuals with active coronal or root decay are more likely to have a history of tobacco and to be male. Those patients are less likely to have regular dental visits $[6,27]$.

Oral health crucially depends on health attitudes, mainly adequate oral hygiene and regular dental visits. Even toothless patients require periodic dental visits to control the state of dentures, the mucous membrane of the toothless alveoli of the maxilla and mandible, as well as the temporo-mandibular joint. Each patient should also be subject to oncological prophylaxis. It is a significant role of the dentist to convince elderly patients about the significance of oral control. In 1973, Marc Lalonde presented the Health Field Concept, which included four determinants: human biology, environment, lifestyle, and health care organisation. The Lalonde idea assumes that lifestyle is the most important health factor: "an aggregation of decisions by individuals, which affect their health and over which they more or less have control" [13]. Health attitudes are shaped from an early age and have a significant influence on decisions and attitudes at later stages of life. The essential task of health education is to educate the patient about the negative and positive effects of attitudes. Education, health promotion, and preventive programs make it possible to know and understand the significance of health attitudes and the factors that shape them [3].

\section{MATERIAL AND METHODS}

A group of 2500 people were randomly selected by the Ministry of the Interior and Administration using a two-tier drawing method (gender and age). From this group, 294 people aged 65-74 years living in the West Pomerania Region were included in the study, with the reporting rate at only $11.76 \%$. The study included the city of Szczecin (population in 2016: 405,413) and the towns of Eobez $(10,409)$ and Police $(33,152)$ [4] and was conducted at the turn of the year 2014/2015. The exclusion criteria of the study included general contraindications (e.g. endocarditis in the interview) or local contraindications (e.g. acute oral inflammation). The examined individuals were noninstitutionalised and they were invited by a letter to the Clinic of Periodontics of the Pomeranian Medical University in Szczecin. The participants answered questions about: the number of dental visits per year, the frequency of brushing teeth or dentures per day, frequency of toothbrush or denture brush replacement during the year (if there were differences between frequency of brushing teeth and brushing dentures or frequency of replacement toothbrush or denture brush, the worst condition was accepted), cleaning of interdental spaces, the most common reasons for dental visits (follow-up visits, toothache visits, improvement of dental aesthetics, gingival bleeding, and other causes), and the source of dental treatment funding (only in state-financed facilities - National Health Fund, only in private facilities, or mixed). Clinical examinations were performed under artificial lighting conditions, with dental mirrors and a dental probe, and without any additional magnifying devices. The study considered the 28 permanent teeth, excluding wisdom teeth. In the clinical study, dentition was evaluated using the DMFT index, which includes the average number of decayed (D), missing (M), and filled (F) teeth in the study population. All teeth were categorised according to the Oral Health Survey basic methods fourth edition guidelines [30]. Caries were recorded as present when a lesion in a pit or fissure, or on a smooth tooth surface, had an unmistakable cavity, undermined enamel, or a detectably softened floor or wall. Teeth with a temporary filling, or one that was sealed but also decayed, was also included in this category. Wisdom teeth were not taken into account in the study. Edentate individuals were included in the examination.

Results were analysed statistically using STATA 11 statistical software. The probability in this model was calculated by Pearson's $\chi^{2}$ test. Frequencies, means (SD), and line charts were generated using Student's $t$-test for hypothesis of equality of means in two groups and ANOVA test variance analysis in more than two groups of participants. Differences in all tests were deemed statistically significant at $p<0.05$.

Approval to undertake the study was obtained from the Bioethics Commission of the Medical University of Warsaw, Poland (KB/24/2011).

\section{RESULTS}

As shown in Table 1, 220 people (74.8\%) - comprising 127 women $(77.9 \%)$ and 93 men $(71 \%)$ - declared at least one dental visit per year, and 74 people (25.2\%) stated less than once a year or not at all. One hundred 
and six people (36\%) reported just one dental visit a year, 77 people $(26.2 \%)$ reported dental visits twice a year, and 37 patients $(12.6 \%)$ three or more visits a year. The annual frequency of dental visits did not differ statistically significantly between the sexes.

Table 2 shows that dental visits were mainly follow-up visits (152 persons, $51.7 \%)$. There were 107 people (36.4\%) - comprising 51 women (31.3\%) and 56 men (42.8\%) reporting toothache as their most frequent cause of dental visits $(p=0.05)$. Improving dental aesthetics was the least popular cause (11 people, 3.75\%), together with gingival bleeding (11 people, $3.75 \%$ ).

Most patients brushed their teeth and/or dentures twice a day (188 persons, 63.9\%). There were 11 patients $(3.7 \%)$ - including six women $(3.7 \%)$ and five men $(3.8 \%)$ - who did so less than once a day or not at all. Again, there were no sex-related differences (Table 3).

As shown in Table 4, 72 people $(24.5 \%)$ replaced their toothbrush and/or denture brush twice a year. There were 20 people $(6.8 \%)$ - including 10 women $(6.1 \%)$ and
10 men $(7.6 \%)$ - who did so less than once a year or not at all. The frequency of toothbrush and/or denture brush replacement was not related to sex.

Only 60 people $(20.4 \%)$ declared cleaning interdental spaces (Table 5). This was the only aspect of oral hygiene that showed a statistically significant difference between sexes, with much worse results among men than among women $(15.3 \%$ vs. $24.5 \%, p=0.04)$.

As can be seen in Table 6, health attitudes significantly affected the dental health of the elderly subjects. The average number of missing teeth was 13.09 , and average DMFT index in the examined population was 21.1. Subjects whose dental visits were usually follow-up visits had the lowest mean number of missing teeth, at 11.2 ( $\mathrm{SD}=7.5, p=0.0001)$, and the highest mean number of filled teeth, at $8.2(\mathrm{SD}=5.1, p=0.00001)$. In contrast, the highest average number of missing teeth was found among subjects with the worst dental health attitudes. Those with the lowest frequency of dental visits or no dental visits had 18.3 missing teeth on average $(\mathrm{SD}=9.1$,

TABLE 1. Annual frequency of dental visits $(n=294)$

\begin{tabular}{|c|c|c|c|c|c|}
\hline Number of dental visits per year & $\begin{array}{l}\text { Female } \\
\text { No. (\%) }\end{array}$ & $\begin{array}{c}\text { Male } \\
\text { No. (\%) }\end{array}$ & $\begin{array}{c}\text { Total } \\
\text { No. (\%) }\end{array}$ & $\chi^{2}$ & $p$-value \\
\hline Less than once a year or not at all & $36(22.1)$ & $38(29)$ & $74(25.2)$ & \multirow[t]{4}{*}{4.98} & \multirow[t]{4}{*}{0.17} \\
\hline Once a year & $55(33.7)$ & $51(38.9)$ & $106(36)$ & & \\
\hline Twice a year & $50(30.7)$ & $27(20.6)$ & $77(26.2)$ & & \\
\hline Three times a year or more & $22(13.5)$ & $15(11.4)$ & $37(12.6)$ & & \\
\hline Total & $163(100)$ & $131(100)$ & $294(100)$ & & \\
\hline
\end{tabular}

TABLE 2. The most common causes of dental visits $(n=294)$

\begin{tabular}{|c|c|c|c|c|}
\hline The most common cause of a dental visit & $\begin{array}{l}\text { Female } \\
\text { No. (\%) }\end{array}$ & $\begin{array}{c}\text { Male } \\
\text { No. (\%) }\end{array}$ & $\begin{array}{c}\text { Total } \\
\text { No. (\%) }\end{array}$ & $p$-value \\
\hline Follow-up visit & $87(53.4)$ & $65(49.6)$ & $152(51.7)$ & 0.35 \\
\hline Toothache & $51(31.3)$ & $56(42.8)$ & $107(36.4)$ & 0.05 \\
\hline Improving the aesthetics of the dentition & $6(3.7)$ & $5(3.8)$ & $11(3.75)$ & 0.95 \\
\hline Gingival bleeding & $8(4.9)$ & $3(2.3)$ & $11(3.75)$ & 0.24 \\
\hline Other reasons & $11(6.7)$ & $2(1.5)$ & $13(4.4)$ & 0.03 \\
\hline Total & $163(100)$ & $131(100)$ & $294(100)$ & \\
\hline
\end{tabular}

TABLE 3. Daily frequency of brushing teeth and/or dentures

\begin{tabular}{|c|c|c|c|c|c|}
\hline $\begin{array}{l}\text { Daily frequency of brushing teeth } \\
\text { and/or dentures }\end{array}$ & $\begin{array}{l}\text { Female } \\
\text { No. }(\%)\end{array}$ & $\begin{array}{c}\text { Male } \\
\text { No. (\%) }\end{array}$ & $\begin{array}{c}\text { Total } \\
\text { No. (\%) }\end{array}$ & $\chi^{2}$ & $p$-value \\
\hline Less than once a day or not at all & $6(3.7)$ & $5(3.8)$ & $11(3.7)$ & \multirow[t]{4}{*}{5.66} & \multirow[t]{4}{*}{0.13} \\
\hline Once a day & $25(15.3)$ & $30(22.9)$ & $55(18.7)$ & & \\
\hline Twice a day & $104(63.8)$ & $84(64.1)$ & $188(63.9)$ & & \\
\hline Three times a day or more often & $28(17.2)$ & $12(9.2)$ & $40(13.6)$ & & \\
\hline Total & $163(100)$ & $131(100)$ & $294(100)$ & & \\
\hline
\end{tabular}


TABLE 4. Annual frequency of replacing toothbrush and/or denture brush

\begin{tabular}{|c|c|c|c|c|c|}
\hline $\begin{array}{l}\text { Annual frequency of replacing } \\
\text { toothbrush and/or denture brush }\end{array}$ & $\begin{array}{l}\text { Female } \\
\text { No. (\%) }\end{array}$ & $\begin{array}{l}\text { Male } \\
\text { No. }(\%)\end{array}$ & $\begin{array}{l}\text { Total } \\
\text { No. }(\%)\end{array}$ & $\chi^{2}$ & $p$-value \\
\hline Less than once a year or not at all & $10(6.1)$ & $10(7.6)$ & $20(6.8)$ & \multirow[t]{6}{*}{6.02} & \multirow[t]{6}{*}{0.30} \\
\hline Once a year & $19(11.7)$ & $21(16)$ & $40(13.6)$ & & \\
\hline Twice a year & $39(23.9)$ & $33(25.2)$ & $72(24.5)$ & & \\
\hline Three times a year & $30(18.4)$ & $20(15.3)$ & $50(17)$ & & \\
\hline Four times a year & $29(17.8)$ & $30(22.9)$ & $59(20.1)$ & & \\
\hline Five times a year or more & $36(22.1)$ & $17(13)$ & $53(18)$ & & \\
\hline Total & $163(100)$ & $131(100)$ & $294(100)$ & & \\
\hline
\end{tabular}

TABLE 5. Number and percentage of people cleaning interdental spaces $(n=294)$

\begin{tabular}{|l|c|c|c|c|c|}
\hline \multirow{2}{*}{ Cleaning interdental spaces } & \multicolumn{2}{c}{ Female } & \multicolumn{2}{c}{ Male } & \multicolumn{2}{c|}{ Total } & \multicolumn{2}{c|}{$\chi^{2}$} & \multicolumn{1}{c|}{$\boldsymbol{p}$-value } \\
\hline Yes & No. (\%) & No. (\%) & $60(20.4)$ & \multirow{2}{*}{3.84} & 0.04 \\
\hline No & $40(24.5)$ & $20(15.3)$ & $234(79.6)$ & & \\
\hline Total & $123(75.5)$ & $111(84.7)$ & $294(100)$ & & \\
\hline
\end{tabular}

$p=0.00001)$; those who replaced their toothbrush and/ or denture brush less than once a year or not at all had on average 20.1 teeth missing ( $\mathrm{SD}=10.3, p=0.00001)$, while those who brushed their teeth and/or dentures less than once a day had on average 24.6 missing teeth ( $\mathrm{SD}=7, p=0.00001$ ). The average number of missing teeth in those not cleaning their interdental spaces was $14.3(\mathrm{SD}=8.2$ ), which was two times higher than among the people using some form of interdental cleaning, at 7.2 missing teeth $(\mathrm{SD}=5.3, p=0.00001)$.

As shown in Table 6, the highest values of the average number of filled teeth were found among the people with the best health attitudes: two dental visits a year $8.9(\mathrm{SD}=4.7)$ and more than two dental visits a year -8.6 $(\mathrm{SD}=4.7, p=0.00001)$; brushing teeth and/or dentures three times or more a day $-8(\mathrm{SD}=4.9, p=0.00001)$, replacing toothbrush and/or denture brush five times or more a year $-9.4(\mathrm{SD}=5, p=0.001001)$; and cleaning interdental spaces $-10(\mathrm{SD}=4.7, p=0.00001)$.

The average DMFT index was greatest in elderly subjects who had a dental visit less than once a year or not at all $-22.9(\mathrm{SD}=6.1, p=0.005)$, brushed teeth and/or dentures less than once a day or not at all -27.3 $(\mathrm{SD}=2.1, p=0.0006)$, replaced their toothbrush and/or denture brush less than once a year or not at all - 24.7 ( $\mathrm{SD}=4.8, p=0.00001)$, and did not clean their interdental spaces $-21.7(\mathrm{SD}=5.3, p=0.00001)$ (Table 6).

As shown in Table 7, there were statistically significant differences when comparing dental treatment funding and the values of the average number of missing (M), filled (F), and DMFT. Mean number of missing teeth was found to be almost twice as high in the group of respondents using only state financed facilities com- pared with people using only private facilities $(\mathrm{SD}=18.1$ vs. $\mathrm{SD}=9.7)$. The difference in relation to the value of the average number of filled teeth was even more noticeable $(\mathrm{SD}=3.7$ vs. $\mathrm{SD}=9.4)$.

\section{DISCUSSION}

A comparison of self-reported dental health attitudes with currently available literature is problematic due to the insufficient number of regional epidemiological studies relevant to oral health behaviours in young seniors. There is a lack of research comparing health attitudes and the dentition of older persons. One of the main problems of dental aging is loss of teeth and associated complications. Dental caries are still the main cause of tooth loss in young seniors $[6,27]$. The increase in the number of older adults in the coming years should raise the interest of governments in the implementation and financing of the necessary epidemiological studies in this age group. Analysis of the results of epidemiological studies makes it possible to propose an appropriate preventive program for oral health among older people and provides a basis for discussion on the rational spending of public funds for dental prophylaxis and treatment.

The oral hygiene habits in the older adult residents of West Pomerania are insufficient. This is confirmed by another Polish and European regional and national studies. In a study conducted in Wrocław (2017) only $68.4 \%$ attempted to maintin regular dental appointments (at least once a year) [12]. Comparable results were observed in Pisa (Italy, 2011), at 70\% [26]. In the study of elderly participants in West Pomerania 
TABLE 6. Mean number of decayed (D), missing (M), and filled (F) teeth, and the DMFT index vs. health attitudes

\begin{tabular}{|c|c|c|c|c|c|c|c|c|}
\hline \multirow[t]{2}{*}{ Categories } & \multicolumn{2}{|c|}{$\begin{array}{l}\text { Average number } \\
\text { of decayed teeth }\end{array}$} & \multicolumn{2}{|c|}{$\begin{array}{l}\text { Average number } \\
\text { of missing teeth }\end{array}$} & \multicolumn{2}{|c|}{$\begin{array}{l}\text { Average number } \\
\text { of filled teeth }\end{array}$} & \multicolumn{2}{|c|}{ Average DMFT index } \\
\hline & Mean (SD) & $p$-value & Mean (SD) & $p$-value & Mean (SD) & $p$-value & Mean (SD) & $p$-value \\
\hline Total & 1.1 & & 13.09 & & 6.91 & & 21.1 & \\
\hline \multicolumn{9}{|l|}{ Sex } \\
\hline Female & 0.9 & \multirow[t]{2}{*}{0.1} & 13.4 & \multirow[t]{2}{*}{0.63} & 7.1 & \multirow[t]{2}{*}{0.5} & 21.4 & \multirow[t]{2}{*}{0.4} \\
\hline Male & 1.3 & & 12.8 & & 6.7 & & 20.7 & \\
\hline \multicolumn{9}{|c|}{ Place of residence } \\
\hline City & 1.2 & \multirow[t]{2}{*}{0.15} & 12.6 & \multirow[t]{2}{*}{0.001} & 7.3 & \multirow[t]{2}{*}{0.07} & 21.0 & \multirow[t]{2}{*}{0.4} \\
\hline Town & 0.8 & & 14.7 & & 5.9 & & 21.4 & \\
\hline \multicolumn{9}{|c|}{ The most common cause of a dental visit } \\
\hline Follow-up & $1.1(1.5)$ & 0.41 & $11.2(7.5)$ & 0.0001 & $8.2(5.1)$ & 0.00001 & $20.5(4.9)$ & 0.02 \\
\hline Pain & $1.2(1.6)$ & 0.35 & $13.4(7.8)$ & 0.48 & $6(4.7)$ & 0.03 & $20.6(5.6)$ & 0.37 \\
\hline Aesthetics & $1.6(2.1)$ & 0.21 & $12.2(3.8)$ & 0.93 & $6.6(4.8)$ & 0.95 & $20.4(4)$ & 0.54 \\
\hline Bleeding & $0.3(0.6)$ & 0.04 & $16.1(9.7)$ & 0.26 & $5.5(4.5)$ & 0.40 & $21.9(6.1)$ & 0.53 \\
\hline Country & $0.7(1.7)$ & 0.10 & $18(9.4)$ & 0.05 & $6.1(7)$ & 0.26 & $24.8(4.8)$ & 0.009 \\
\hline \multicolumn{9}{|c|}{ Number of dental visits per year } \\
\hline 0 & $1(1.7)$ & \multirow[t]{4}{*}{0.69} & $18.3(9.1)$ & \multirow[t]{4}{*}{0.00001} & $3.7(4.9)$ & \multirow[t]{4}{*}{0.00001} & $22.9(6.1)$ & \multirow[t]{4}{*}{0.005} \\
\hline 1 & $1.2(1.5)$ & & $12.4(7.5)$ & & $7.1(4.8)$ & & $20.7(5)$ & \\
\hline 2 & $1(1.3)$ & & $10.1(6.5)$ & & $8.9(4.7)$ & & $20(4.9)$ & \\
\hline$\geq 3$ & $1.3(1.9)$ & & $10.9(7.1)$ & & $8.6(4.7)$ & & $20.8(4.7)$ & \\
\hline \multicolumn{9}{|c|}{ Daily frequency of brushing teeth and/or dentures } \\
\hline$<1$ & $0.5(1.8)$ & \multirow[t]{4}{*}{0.01} & $24.6(7)$ & \multirow[t]{4}{*}{0.00001} & $2.1(6.9)$ & \multirow[t]{4}{*}{0.00001} & $27.3(2.1)$ & \multirow[t]{4}{*}{0.0006} \\
\hline 1 & $1.7(1.9)$ & & $15.1(8)$ & & $4.9(4.4)$ & & $21.6(5.1)$ & \\
\hline 2 & $1(1.4)$ & & $12.1(7.8)$ & & $7.6(5.1)$ & & $20.6(5.3)$ & \\
\hline$\geq 3$ & $0.9(1.6)$ & & $11.8(8.2)$ & & $8(4.9)$ & & $20.8(5.2)$ & \\
\hline \multicolumn{9}{|c|}{ Annual frequency of replacing toothbrush and/or denture brush } \\
\hline 0 & $1.2(2.2)$ & 0.33 & $20.1(10.3)$ & 0.00001 & $3.4(6.3)$ & 0.00001 & $24.7(4.8)$ & 0.00001 \\
\hline 1 & $1(1.3)$ & & $17(8.2)$ & & $5.5(5.1)$ & & $23.5(5.3)$ & \\
\hline 2 & $1.3(1.7)$ & & $15.4(7.7)$ & & $5.4(4.6)$ & & $22.1(4.7)$ & \\
\hline 3 & $0.8(1.1)$ & & $12.2(7.5)$ & & $7.18(4.3)$ & & $20.2(5.7)$ & \\
\hline 4 & $1.4(1.7)$ & & $9.3(6.6)$ & & $8.4(5.1)$ & & $19(4.9)$ & \\
\hline$\geq 5$ & $0.9(1.4)$ & & $9.4(6.5)$ & & $9.4(5)$ & & $19.7(4.9)$ & \\
\hline Cleaning interde & I spaces & & & & & & & \\
\hline Yes & $1.4(1.8)$ & 0.12 & $7.2(5.4)$ & 0.00001 & $10(4.7)$ & 0.00001 & $18.6(4.6)$ & 0.00001 \\
\hline No & $1.1(1.5)$ & & $11.2(7.5)$ & & $8.2(5.1)$ & & $20.5(4.9)$ & \\
\hline
\end{tabular}

a slightly better result was observed $(74.8 \%)$. Regular tooth brushing (at least twice a day) was observed only in $71.7 \%$ of Wrocław's young seniors and in $77 \%$ of elderly participants in Pisa [12, 26]. Considering the methodology of this study (inseparable daily frequency of brushing teeth and/or brushing dentures), observations of the study in West Pomeranian older adult individuals (77.5\%) ought to be interpreted carefully. The proportion of persons who clean their inter- dental spaces regularly (every day) was $20.4 \%$ in West Pomerania, $18.9 \%$ in Wrocław, and $27 \%$ in Pisa [12, 26]. National Polish epidemiological survey data on oral health from 2015 showed a low health attitude in Poles aged from 65 to 74 years. As many as $78.3 \%$ of the respondents reported a dental visit at least once a year, with pain as the main cause $(48.8 \%)$. Only one quarter reported a regular (at least once a year) visit to the dentist's office. It was found that $5.7 \%$ of Poles 
TABLE 7. Mean number of decayed (D), missing (M), and filled (F) teeth, and the DMFT index vs. dental treatment funding

\begin{tabular}{|c|c|c|c|c|c|}
\hline \multirow{2}{*}{\multicolumn{2}{|c|}{ Categories }} & \multicolumn{4}{|c|}{ Dental treatment funding } \\
\hline & & Only in statefinanced facilities & Only in private facilities & Mixed & $p$-value \\
\hline \multirow{5}{*}{ Caries mean (SD) } & Total & $73(24.8)$ & $97(33)$ & $124(42.2)$ & \\
\hline & Decayed (D) & 1.0 & 0.9 & 1.31 & 0.11 \\
\hline & Missing (M) & 18.1 & 9.7 & 12.7 & 0.00001 \\
\hline & Filled (F) & 3.7 & 9.4 & 6.8 & 0.00001 \\
\hline & DMFT & 22.9 & 20 & 20.9 & 0.002 \\
\hline
\end{tabular}

did not use a toothbrush to brush teeth or dentures, and $19.2 \%$ did not use a toothbrush or did not replace a toothbrush or denture brush within a year. It was observed that only $17.2 \%$ of Poles cleaned their interdental spaces [11].

Only three Polish cross-sectional studies of persons aged 65-74 years considering DMFT index have been found in the medical literature from recent years $[12,18$, 24]. The mean value of the DMFT index for the whole group of West Pomeranian elderly persons was 21.1 (D - 1.1, M - 13.09, F - 6.91), and it was higher than in a regional study in Wrocław (DMF - 17.45, D - 1.04, $\mathrm{M}$ - 11.97, F - 4.42) [12]. In comparison, for males from West Pomerania, in an analogous study of men from Białystok, the mean value of DMFT (20.7 vs. 16.31) and the mean value of M (12.8 vs. 10.91) was higher. The mean number of decayed teeth in elderly men in West Pomerania was twice as low (1.3 vs. 2.95), and there were over twice as many filled teeth (6.7 vs. 2.45$)$ compared with the study conducted in Białystok [24]. The mean number of missing teeth among the elderly participants in Lublin was similar (13.6) [18]. A worse situation regarding the DMFT index was observed in a regional study of the Kosovar population aged 65-74 years. The mean value of missing teeth in Kosovar was higher, at 16.06, and only 0.77 teeth were filled (DMF $17.98, \mathrm{D}-1.14$ ) [9].

The source of dental treatment funding may indirectly affect the quality of treatment. The absence of one's own financial means has an impact on access to dental procedures. For example, in the Polish National Health Fund endodontic treatment of premolars and molars, permanent prosthetic restorations, or periodontal surgery are not refundable. Some similarities in relation to dental caries were found in the Wrocław area. The average DMFT index in the group of persons using only private dental services in the capital of Lower Silesia was 16.4 (D - 0.88, M - 9.37 and $\mathrm{F}-6.29$ ) [12].

A major limitation of the study was the low response to the invitation of older adult individuals to participate. Only $11.76 \%$ of the invited persons reported to the examination, which shows the low representativeness of participants. In comparison, in the case of the study Health in Pomerania, the percentage of reportability was $65.2 \%$ for women and $74.3 \%$ for men in the age range 60-69 years [7]. The study was conducted only in urban areas. Rural residents were excluded from the study, which could also influence the assessment of the results. Another limitation of this study was a failure to include root caries. Root caries are a serious cause of tooth loss in elderly individuals, and tooth loss is the most significant oral health-related negative variable of quality of life for older adults [22]. Finally, one of the limitation was inseparable annual frequency of replacing a toothbrush and/or denture brush and daily frequency of brushing teeth and/ or brushing dentures. Some elderly patients brushed their teeth but did not brush dentures. In some individuals there were differences between the frequency of replacing their toothbrush and denture brush. This should be duly taken into account in epidemiological studies in future.

\section{CONCLUSIONS}

Oral health attitudes among older people in the region of West Pomerania are inadequate and should be improved. The lack of awareness of older people regarding the need for regular follow-up visits means that a large group go to the dentist only because of toothache. Interdental spaces are cleaned by a low proportion of older people in the region. Dental health attitudes had a significant effect on the dentition status expressed by the DMFT index and its components. Studies in this area seem to be essential for the preparation of adequate maintenance programs for oral health. These results can be used in a discussion on the rational spending of public funds on education, prophylaxis, and treatment. Further improvement in the oral health of older people depends crucially on systematic and repeatable regional and national epidemiological research in Poland and throughout the world.

\section{CONFLICT OF INTEREST}

The authors declare no potential conflicts of interest with respect to the research, authorship, and/or publication of this article. 


\section{References}

1. Banasr FH. Prosthetic status and needs of Saudi geriatric edentulous patients in Jeddah. Cairo Dent J 2008; 24: 537-543.

2. Beck JD. The epidemiology of root surface caries: North American studies. Adv Dent Res 1993; 7: 42-51.

3. Blaggana A, Grover V, Anjali. Oral health knowledge, attitudes and practice behaviour among secondary school children in Chandigarh. J Clin Diagn Res 2016; 10: 1-6.

4. Central Statistical Office in Poland: Population. 2016; 234-236.

5. Fitzpatrick J. Oral health care needs of dependent older people: responsibilities of nurses and care staff. J Adv Nurs 2000; 32: 1325-1332.

6. Gati D, Vieira AR. Elderly at greater risk for root caries: a look at the multifactorial risks with emphasis on genetics susceptibility. Int J Dent 2011; 2011: 1-6.

7. Holtfreter B, Schwahn Ch, Biffar R, Kocher T. Epidemiology of periodontal diseases in the study of health in Pomerania. J Clin Periodontol 2009; 36: 114-123.

8. Jensen PM, Saunders RL, Thierer T, et al. Factors associated with oral health-related quality of life in community-dwelling elderly persons with disabilities. J Am Geriatr Soc 2008; 56: 711-717.

9. Kamberi B, Koçani F, Begzati A, et al. Prevalence of dental caries in Kosovar adult population. Int J Dent 2016; 2016: 4290291.

10. Kandelman D, Petersen PE, Ueda H. Oral health, general health, and quality of life in older people. Spec Care Dent 2008; 28: 224-236.

11. Konopka T, Dembowska E, Pietruska M, et al. Periodontal status and selected parameters of oral condition of Poles aged 65 to 74 years. Przegl Epidemiol 2015; 69: 643-647.

12. Konopka T, Głowacka B, Toczewska J, Zawada Ł, Chrzęszczyk D. Oral health parameters in the regional study among young seniors in an urban area of Wrocław. Dent Med Probl 2017; 54: 369-382.

13. Lalonde M. A new perspective on the health of Canadians, a working document. Ottawa 1974; 4: 31-34.

14. Lenander-Lumikari M, Loimaranta V. Saliva and dental caries. Adv Dent Res 2000; 14: 40-47.

15. Locker D, Matear D, Stephens M, et al. Oral health-related quality of life of a population of medically compromised elderly people. Community Dent Health 2002; 19: 90-97.

16. Naito M, Yuasa H, Nomura Y, et al. Oral health status and health related quality of life: a systematic review. J Oral Sci 2006; 48: 1-7.

17. Närhi TO, Meurman JH, Ainamo A. Xerostomia and hyposalivation: causes, consequences and treatment in the elderly. Drugs Aging 1999; 15: 103-116.

18. Panasiuk L, Kosiniak-Kamysz W, Horoch A, Paprzycki P, Karwat D Tooth loss among adult rural and urban inhabitants of the Lublin Region. Ann Agr Env Med 2013; 20: 637-641.

19. Petersen PE, Kandelman D, Arpin S, et al. Global oral health of older people- call for public health action. Community Dent Health 2010; 27: 257-268.

20. Petersen PE. The World Oral Health Report 2003: continuous improvement of oral health in the $21^{\text {st }}$ century - the approach of the WHO Global Oral Health Programme. Community Dent Oral Epidemiol 2003; 31 Suppl 1: 3-23.

21. Petersen PE, Yamamoto T. Improving the oral health of older people: the approach of the WHO Global Oral Health Programme. Community Dent Oral Epidemiol 2005; 33: 81-92.

22. Saunders RH, Meyerowitz C. Dental caries in older adults. Dent Clin North Am 2005; 49: 293-308.

23. Slavkin HC. Maturity and oral health: live longer and better. J Am Dent Assoc 2000; 131: 805-808.

24. Szpak A, Stokowska W, Gołębiewska E. Dentition status and treatment needs of 65-74-year-old men living in Bialystok. Probl Hig Epidemiol 2012; 93: 97-104 [In Polish].

25. Thomson WM. Epidemiology of oral health conditions in older people. Gerodontology 2014; 31: 9-16.

26. Vano M, Gennai S, Karapetsa D, et al. The influence of educational level and oral hygiene behaviours on DMFT index and CPITN index in an adult Italian population: An epidemiologic study. Int J Dent Hyg 2015; 13: 151-157.

27. Warren JJ, Cowen HJ, Watkins CM, Hand JS. Dental caries prevalence and dental care utilization among the very old. J Am Dent Assoc 2000; 131: 1571-1579.

28. World Health Organization. A glossary terms for community health care and services for older persons. Aging and health technical report, $2004 ; 31$.

29. World Health Organization. National Institute on Aging: Rising numbers of the oldest old. Why Population Aging Matters: A Global Perspective, 2011; 8-9.

30. World Health Organization. Oral health surveys. Basic methods. $4^{\text {th }}$ ed. Geneva, 1997. 